\title{
Transformer's Load Forecasting to Find the Transformer Usage Capacity with Adaptive Neuro-Fuzzy Inference System Method
}

\author{
I. Gde Made Yoga Semadhi Artha, Ida Bagus Gede Manuaba \\ Department of Electrical Engineering, Udayana University, Denpasar, Indonesia \\ Email address: \\ yogaunudpower@gmail.com (I. G. M. Y. S. Artha), ibgmanuaba@unud.ac.id (I. B. G. Manuaba)
}

To cite this article:

I. Gde Made Yoga Semadhi Artha, Ida Bagus Gede Manuaba. Transformer's Load Forecasting to Find the Transformer Usage Capacity with Adaptive Neuro-Fuzzy Inference System Method. Journal of Electrical and Electronic Engineering. Vol. 7, No. 1, 2019 , pp. 1-7. doi: $10.11648 /$ j.jeee.20190701.11

Received: October 31, 2018; Accepted: November 27, 2018; Published: January 24, 2019

\begin{abstract}
The development of the tourist destinations of Bali Island, especially Nusa Dua area, should be included with the development of electricity supply in the region. To facilitate a process of electrical energy planning in the region, it is necessary to forecast the electrical load in the area. Forecasting is a process to estimate future events / things to come. In this research, the forecasting of the long-term electrical load for five years and this forecasting method using ANFIS method and use ANN method as a comparison. From the simulation conducted by MAPE which resulted from forecasting the weekly electrical load using ANFIS method is $0.028 \%$ while MAPE forecasting using ANN method is $51.57 \%$. From the comparison result, it can be said that the annual electricity load forecasting using the ANFIS method has a better forecasting accuracy than using the ANN method. The forecasting results of this transformer load is used as a reference in planning the electricity system on the Bali Island.
\end{abstract}

Keywords: ANFIS, MAPE, Electrical Load

\section{Introduction}

Bali is a world tourist destination; Nusa Dua area located in badung regency is a tourism area. The development of the number of tourism in badung district is growing rapidly seen from the number of tourists in 2017 which increased about $23.5 \%$ from the previous year.

The development of tourism is very significant must be supported with the electrical system in the area of Nusa Dua. Certainty of electricity supply is one of the factors that must be fulfilled to maintain the tourism in the area, because the electricity needs are increasing every year. If large electricity consumption can be determined, then we can do the planning to always maintain the reliability of the power supply by following the development of electrical loads.

Forecasting is a process to estimate future events / things to come. Forecasting is an essential instrument in science research, and received much attention during the past three decades [1-4]. Forecasting is usually classified based on the future time it encloses, making accurate predictions is not easy, there are several factors to consider [5]. Nowadays short term forecasting is used popularly in many fields such as electric load, traffic flow, stock exchange, disaster and wheather [6-9]. In the field of electric power, forecasting usually in the form of load forecasting (including forecasting of peak load (MW), load capacity usage (Ampere). Forecasting based on time span can be categorized into three: Short term, medium term and long term $[10,11]$.

Long-term forecasting starts from a matter of years to decades. Forecasting has an important role in the context of generation, transmission and distribution network planning in power systems. The ultimate goal of power system planning is to determine the economic expansion of equipment and facilities to meet future electricity needs of customers with acceptable levels of reliability and power quality [12].

The Adaptive Neuro-Fuzzy Inference System (ANFIS) is a method that uses artificial neural networks to implement fuzzy inference systems. This method is chosen because 
ANFIS method has all the advantages possessed by fuzzy inference system and artificial neural network system. With the use of ANFIS method it is expected that the time required to forecast the electrical load can be shorter. For rapid and exact results neural computing techniques are majorly used, which works by training basis. ANFIS is a better approach in improving of Neuro-fuzzy in case of modeling nonlinear functions. The ANFIS sets the system parameters by error norms and learns the system by example data set [13].

In this research, ANFIS method will be used to predict the power load. Forecasting is done to calculate the amount of current on transformers 1, 2 and 3 in Nusa Dua Substation, in the working area of PT PLN (Persero) APB Bali.

\section{Methodology}

\subsection{Adaptive Neuro-Fuzzy Inference System (ANFIS)}

ANFIS is a kind of adaptive neuro-fuzzy inference system which connects fuzzy logic system with neural network and constructs a hybrid intelligent system and benefits from the advantages of both fuzzy logic and neural networks, and its efficiency in very accurate models has been proved [14]. It also makes use of neural learning rules to identify and tune the parameters and structure of a Fuzzy Inference System (FIS). The main features of ANFIS method include fast and accurate learning, strong generalization capabilities, easy implementation, excellent explanation through fuzzy rules and incorporation with linguistic and numeric knowledge [15]. The adaptive neural fuzzy inference system combined the adaptive learning ability of neural network and the experience knowledge of fuzzy inference system, ANFIS has the ability to efficiently identify nonlinear systems [16, 17] and is applied for forecasting Loads in this paper.

\subsection{Architecture of Adaptive Neuro Fuzzy Inference System (ANFIS)}

To make it easier to describe the Adaptive Neuro Fuzzy Inference System (ANFIS) architecture, it is assumed the fuzzy inference system has only two inputs, $x_{1}$ and $x_{2}$, and one output denoted $Y$. In the first order Sugeno model, the rule set uses a linear combination of input- existing inputs that can be expressed as:
Rule 1: IF $x_{1}$ is $A_{1}$ AND $x_{2}$ is $B_{1}$ premise
then
then
$\mathrm{Y}_{1}=\mathrm{p}_{1} \mathrm{x}_{1}+\mathrm{q}_{1} \mathrm{x}_{2}+\mathrm{r}_{1}$ consequent
$\mathrm{Y}_{2}=\mathrm{p}_{2} \mathrm{x}_{1}+\mathrm{q}_{2} \mathrm{X}_{2}+\mathrm{r}_{2}$ consequent

\section{Input: $x_{1}$ and $x_{2}$}

The consequent is an $Y$. so this healing model is:

$$
\frac{w 1 y 1+w 2 y 2}{w 1+w 2}=\overline{w 1}+\overline{w 2}
$$

Next, ANFIS architecture for the case of two inputs, $x_{1}$ and $x_{2}$, and one output denoted $Y$ is illustrated by the following figure:

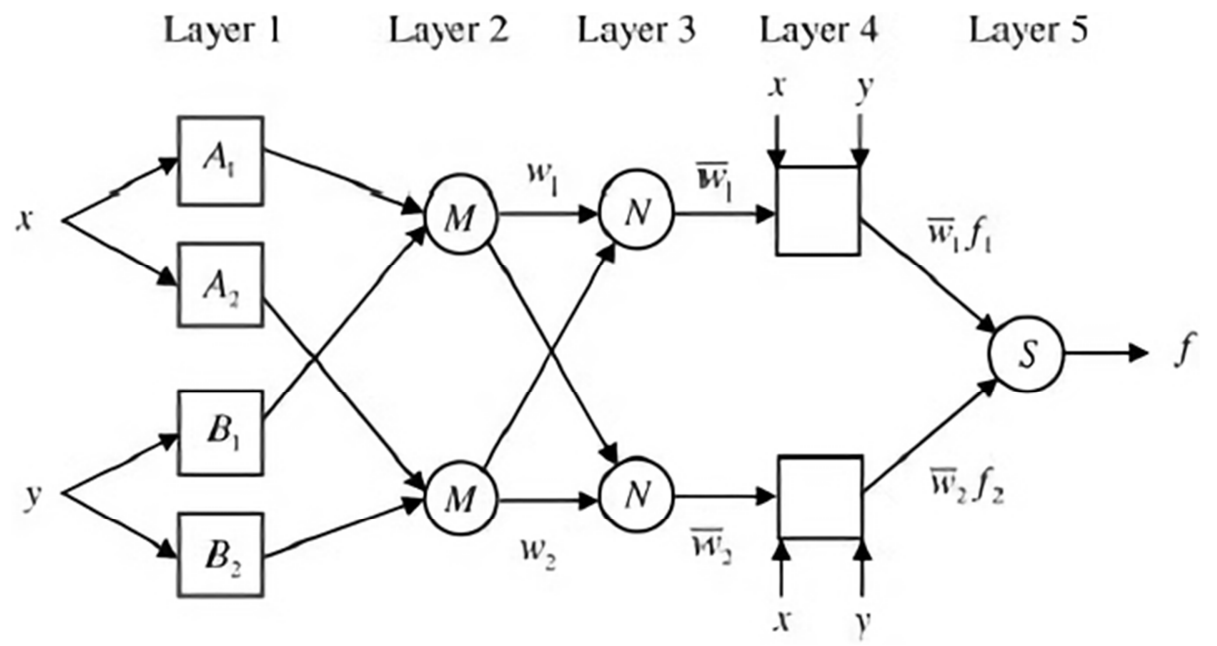

Figure 1. Architecture of ANFIS.

There are five layers, that is:

\subsubsection{Layer 1}

Each node $\mathrm{i}$ in this layer is an adaptive node with a function node:

$$
O_{1, i}=\mu_{A i}\left(x_{1}\right), i=1,2
$$

$$
O_{1, i}=\mu_{B i}\left(x_{2}\right), i=3,4
$$

\subsubsection{Layer 2}

Each node in this layer is labeled $\Pi$ with the output multiplication of all incoming signals, namely:

$$
\mathrm{O}_{2,1}=\mathrm{w}_{1}=\mu_{\mathrm{Ai}}\left(\mathrm{x}_{1}\right) \Delta \mu_{\mathrm{Bi}}\left(\mathrm{x}_{2}\right), \mathrm{i}=1,2
$$


So:

$$
\begin{aligned}
& \mathrm{w}_{1}=\mu_{\mathrm{Ai}}\left(\mathrm{x}_{1}\right) \text { AND } \mu_{\mathrm{A} 1}\left(\mathrm{x}_{2}\right) \\
& \mathrm{w}_{2}=\mu_{\mathrm{A} 2}\left(\mathrm{x}_{1}\right) \text { AND } \mu_{\mathrm{B} 2}\left(\mathrm{x}_{2}\right)
\end{aligned}
$$

Each node output expresses the weight of a rule. Generally the AND operation is used as a function node on this layer

\subsubsection{Layer 3}

Each node in this layer is given $\mathrm{N}$ notation. The node to $-i$ calculates the ratio of the weight of $i^{\text {th }}$ to the sum of all weights:

$$
\mathrm{O}_{3, \mathrm{i}}=\bar{w}_{\mathrm{i}}=\frac{w_{i}}{w_{1}+w_{2}}, i=1,2
$$

\subsubsection{Layer 4}

Each node $i$ in this layer is an adaptive node with a function node:

$$
\mathrm{O}_{4, \mathrm{i}}=\bar{w}_{\mathrm{i}} \mathrm{Y}_{\mathrm{i}}=\bar{w}_{\mathrm{I}}\left(\mathrm{p}_{\mathrm{i}} \mathrm{X}_{1}+\mathrm{q}_{1} \mathrm{X}_{2}+\mathrm{r}_{\mathrm{i}}\right)
$$

\subsubsection{Layer 5}

A single node depicted on this layer serves to aggregate all output from layer 4 (which is defined as the sum of all incoming signals):

$$
\mathrm{O}_{5, \mathrm{i}}=\sum_{i} \bar{w}_{\mathrm{i}} \mathrm{Y}_{\mathrm{i}}=\frac{\sum_{i} W_{i}+Y_{i}}{\sum_{i} W_{i}}
$$

Evaluation of Forecasting Accuracy Adaptive Neuro Fuzzy Inference System (ANFIS)

To measure the extent of the accuracy of ANFIS network output, required a quantization device. To calculate the output difference of ANFIS with the target data in the training process used MSE (Mean Square Error) based on the following equation:

$$
\text { MSE }=\sum_{I=1}^{P} \frac{\mid \text { axtual-estimates }\left.\right|^{2}}{p}
$$

where $\mathrm{P}$ is the number of data pairs. The accuracy of the Adaptive Neuro Fuzzy Inference System (ANFIS) forecasting in this study was calculated using the Absolute Percentage Error (MAPE) Meaning criteria that can be formulated as follows [4]:

$$
\operatorname{MAPE}(\%)=\frac{1}{N} \sum_{i=1}^{N} \frac{\left|p_{h}-p_{h}\right|}{p_{h}} \times 100 \%
$$

Explanation:

$\overline{P h}=$ Actual Load

$(\mathrm{Ph})=$ Actual Load

$\mathrm{N}=$ Number of Data

If the MAPE value is less than $25 \%$ then the forecasting result can be received satisfactory

\section{Result and Discussion}

Power load forecasting that discussed in this study is the forecasting of annual electrical load using ANFIS method which then the result will be compared with forecasting result using ANN method. The data used is the data load in transformer 1, transformer 2, and transformer 3 in Nusa Dua Substation. With the following data:

\subsection{Transformer 1 Data in Nusa Dua Substation}

Table 1. Load data Transformer 1.

\begin{tabular}{llll}
\hline Transformator 1 & $\mathbf{2 0 1 5}(\mathbf{M W})$ & $\mathbf{2 0 1 6}(\mathbf{M W})$ & $\mathbf{2 0 1 7}(\mathbf{M W})$ \\
\hline January & 563.00 & 693.40 & 715.60 \\
February & 525.00 & 642.20 & 756.30 \\
March & 531.00 & 765.60 & 778.10 \\
April & 531.10 & 803.40 & 815.60 \\
May & 625.00 & 797.50 & 834.40 \\
June & 562.50 & 730.90 & 796.90 \\
July & 593.80 & 758.80 & 690.60 \\
August & 687.50 & 834.40 & 715.60 \\
September & 707.95 & 868.80 & 728.10 \\
October & 728.40 & 769.90 & 830.23 \\
November & 748.40 & 740.60 & 773.68 \\
December & 790.00 & 750.00 & 768.42 \\
MAX (MW) & 790.00 & 868.80 & 834.40 \\
Used Capacity (\%) & 45.61 & 50.16 & 48.18 \\
\hline
\end{tabular}

From the table 1 , it is seen that the achievement of transformer 1 in Nusa Dua substation has reached 50.16\%

\subsection{Transformer 2 Data in Nusa Dua Substation}

Table 2. Load data Transformer 2.

\begin{tabular}{llll}
\hline Transformator 2 & $\mathbf{2 0 1 5}(\mathbf{M W})$ & $\mathbf{2 0 1 6}(\mathbf{M W})$ & $\mathbf{2 0 1 7}(\mathbf{M W})$ \\
\hline January & 806.00 & 804.10 & 718.80 \\
February & 669.00 & 754.10 & 781.30 \\
March & 913.00 & 819.70 & 768.80 \\
April & 881.30 & 792.20 & 818.80 \\
May & 771.60 & 689.40 & 806.30 \\
June & 685.50 & 780.00 & 775.00 \\
July & 705.30 & 775.90 & 778.10 \\
August & 958.40 & 809.40 & 790.60 \\
September & 866.25 & 837.50 & 818.80 \\
October & 774.10 & 762.50 & 741.94 \\
November & 792.50 & 775.00 & 762.21 \\
December & 890.30 & 865.60 & 858.67 \\
MAX (MW) & 958.40 & 865.60 & 858.67 \\
Used Capacity (\%) & 55.33 & 49.98 & 49.58 \\
\hline
\end{tabular}

From the table 2, it seen that the achievement of the transformer 2 in Nusa Dua substation has reached 55.33\%

\subsection{Transformer 3 Data in Nusa Dua Substation}

Table 3. Load data Transformer 3.

\begin{tabular}{llll}
\hline Transformator 3 & $\mathbf{2 0 1 5}(\mathbf{M W})$ & $\mathbf{2 0 1 6}(\mathbf{M W})$ & $\mathbf{2 0 1 7}(\mathbf{M W})$ \\
\hline January & 625.00 & 725.90 & 712.50 \\
February & 522.00 & 709.70 & 812.50 \\
March & 750.00 & 800.30 & 750.00 \\
April & 718.80 & 830.00 & 781.30 \\
May & 718.80 & 771.30 & 775.00 \\
June & 625.00 & 752.50 & 690.60 \\
July & 656.30 & 738.40 & 756.30 \\
August & 843.80 & 771.90 & 712.50 \\
September & 791.90 & 809.40 & 771.90 \\
October & 740.00 & 825.00 & 860.46 \\
November & 783.40 & 778.10 & 774.67 \\
December & 854.70 & 778.10 & 883.20 \\
MAX (MW) & 854.70 & 830.00 & 883.20 \\
Used Capacity (\%) & 49.35 & 47.92 & 50.99 \\
\hline
\end{tabular}


FROM the table 3, it seen that the achievement of the transformer 2 in Nusa Dua substation has reached 50.99\%.

For the training phase, use the sample on load data from 2015 - 2017 Transformer $1-3$

Next, using the same input data, the result of the ANFIS forecasting will be compared with the forecast result using ANN method. For sample calculation using data on Transformer 2, so that the comparison of forecasting result as in table 4, and in Figure 2 explains how the structure in ANFIS for data processing.

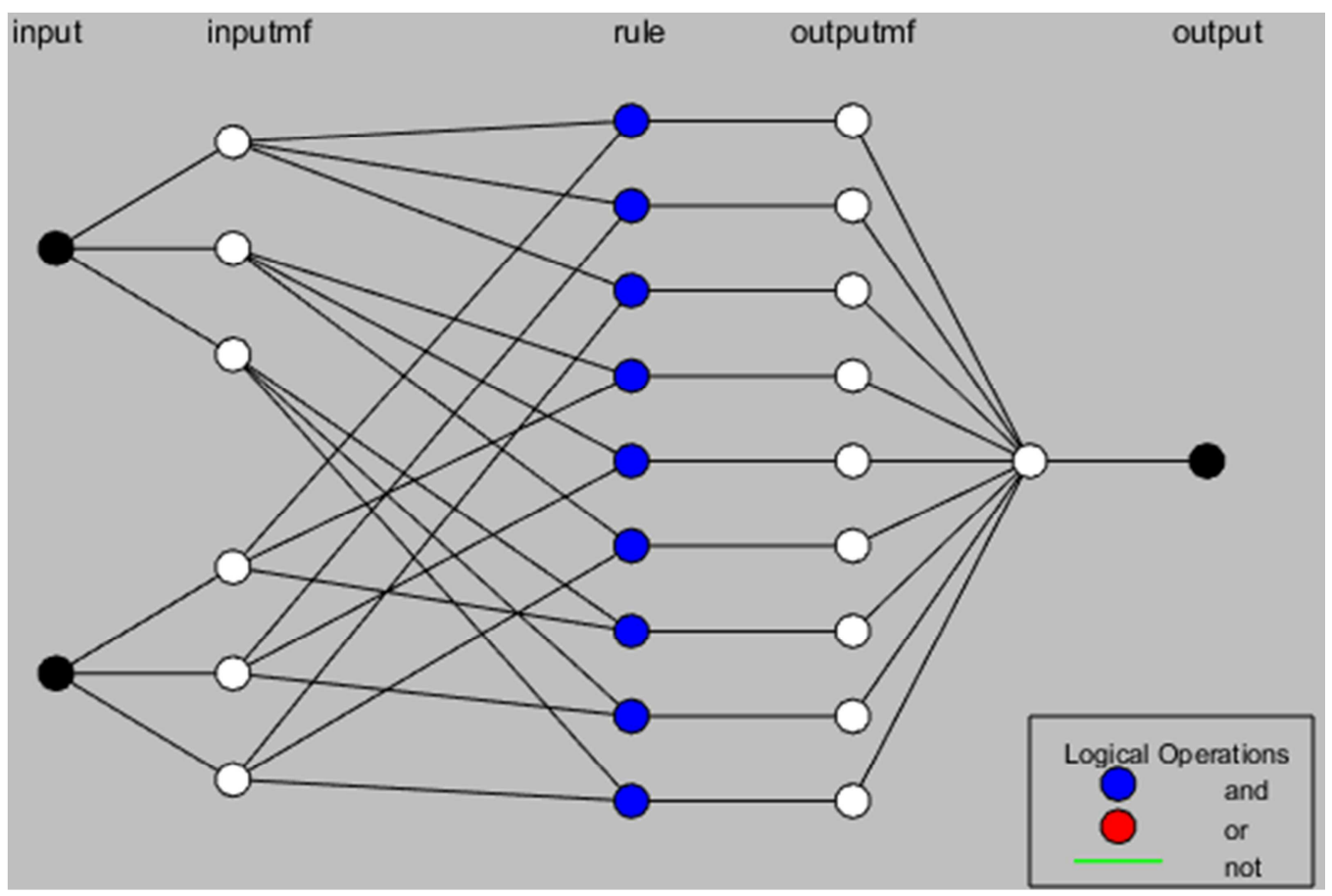

Figure 2. ANFIS Forecasting Structure.

\section{Forecasting Electrical Load}

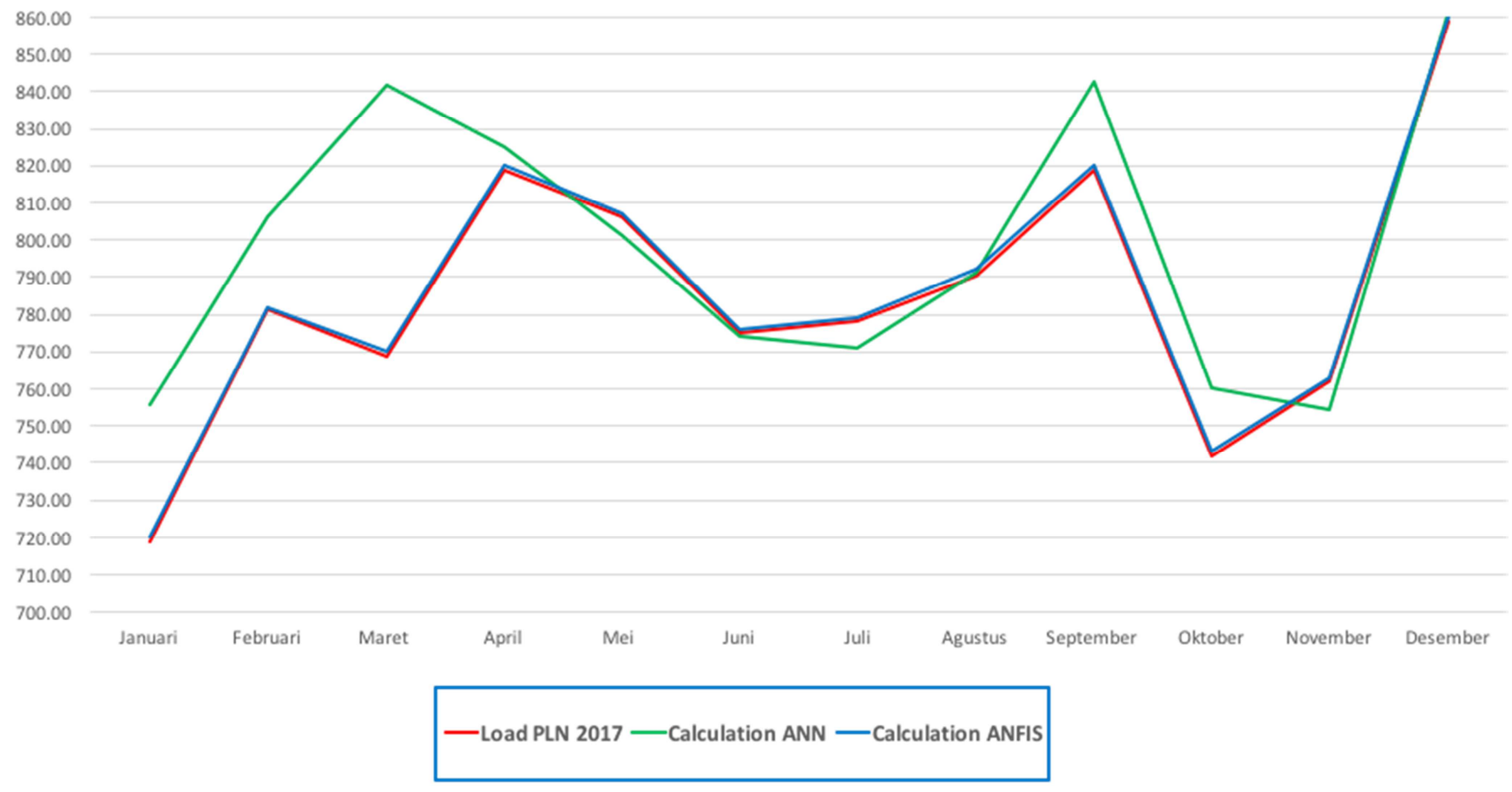

Figure 3. Comparison graph of ANN and ANFIS. 
Table 4. ANN and ANFIS comparison table.

\begin{tabular}{llllll}
\hline MONTH & LOAD PLN 2017 & Calculation ANN & Calculation ANFIS & MAPE ANN & MAPE ANFIS \\
\hline January & 718.80 & 755.87 & 720 & 5.157 & 0.167 \\
February & 781.30 & 806.04 & 782 & 3.167 & 0.090 \\
March & 768.80 & 841.62 & 770 & 9.472 & 0.156 \\
April & 818.80 & 825.09 & 820 & 0.768 & 0.147 \\
May & 806.30 & 801.03 & 807 & 0.654 & 0.087 \\
June & 775.00 & 773.97 & 776 & 0.133 & 0.129 \\
July & 778.10 & 771.17 & 779 & 0.891 & 0.116 \\
August & 790.60 & 791.4 & 792 & 0.101 & 0.177 \\
September & 818.80 & 842.67 & 820 & 2.915 & 0.147 \\
October & 741.94 & 760.32 & 743 & 2.477 & 0.143 \\
November & 762.21 & 754.52 & 763 & 1.009 & 0.103 \\
Desember & 858.67 & 861.43 & 860 & 0.321 & 0.155 \\
\hline
\end{tabular}

From the table 4 and the figure 3 above shows that the accuracy of weekly electrical load forecasting in Bali electricity system using ANFIS method has a higher accuracy rate than forecasting electrical load using ANN method, it can be seen from the MAPE forecasting produced by each method.
Then the long-term forecast calculation is continued by ANFIS Method using data of transformer 1, transformer 2, and transformer 3 . And the following results are obtained.

Forecasting the load and the use of transformer 1 capacity in Nusa Dua substation.

Table 5. Forecasting transformer 1 until 2020.

\begin{tabular}{|c|c|c|c|c|c|c|c|c|}
\hline Transformator 1 & 2015 (MW) & 2016 (MW) & 2017 (MW) & 2018 (MW) & 2019 (MW) & 2020 (MW) & 2021 (MW) & 2022 (MW) \\
\hline January & 563.00 & 693.40 & 715.60 & 745.56 & 775.65 & 811.96 & 851.38 & 893.46 \\
\hline February & 525.00 & 642.20 & 756.30 & 771.32 & 827.97 & 859.60 & 907.55 & 950.06 \\
\hline March & 531.00 & 765.60 & 778.10 & 849.79 & 875.47 & 925.45 & 967.28 & 1017.28 \\
\hline April & 531.10 & 803.40 & 815.60 & 905.04 & 930.19 & 986.65 & 1030.30 & 1084.36 \\
\hline May & 625.00 & 797.50 & 834.40 & 874.90 & 911.48 & 954.90 & 1001.36 & 1050.97 \\
\hline June & 562.50 & 730.90 & 796.90 & 833.59 & 875.66 & 915.76 & 961.95 & 1009.02 \\
\hline July & 593.80 & 758.80 & 690.60 & 746.30 & 758.42 & 802.18 & 836.57 & 880.24 \\
\hline August & 687.50 & 834.40 & 715.60 & 774.35 & 782.27 & 828.52 & 863.08 & 908.51 \\
\hline September & 707.95 & 868.80 & 728.10 & 795.21 & 801.04 & 850.30 & 885.07 & 932.14 \\
\hline October & 728.40 & 769.90 & 830.23 & 832.42 & 879.20 & 912.85 & 960.98 & 1006.48 \\
\hline November & 748.40 & 740.60 & 773.68 & 771.46 & 810.63 & 841.70 & 885.28 & 927.34 \\
\hline December & 790.00 & 750.00 & 768.42 & 764.28 & 800.61 & 831.41 & 873.97 & 915.60 \\
\hline MAX (MW) & 790.00 & 868.80 & 834.40 & 905.04 & 930.19 & 986.65 & 1030.30 & 1084.36 \\
\hline Used Capacity (\%) & 45.61 & 50.16 & 48.18 & 52.25 & 53.71 & 56.97 & 59.49 & 62.61 \\
\hline
\end{tabular}

Forecasting the load and the use of transformer 2 capacity in Nusa Dua substation

Table 6. Forecasting transformer 2 until 2020.

\begin{tabular}{|c|c|c|c|c|c|c|c|c|}
\hline Transformator 2 & 2015 (MW) & 2016 (MW) & 2017 (MW) & 2018 (MW) & 2019 (MW) & 2020 (MW) & 2021 (MW) & 2022 (MW) \\
\hline January & 806.00 & 804.10 & 718.80 & 791.35 & 882.28 & 914.48 & 971.52 & 1014.41 \\
\hline February & 669.00 & 754.10 & 781.30 & 767.51 & 812.94 & 848.17 & 891.43 & 933.39 \\
\hline March & 913.00 & 819.70 & 768.80 & 871.99 & 929.46 & 975.63 & 1025.47 & 1074.79 \\
\hline April & 881.30 & 792.20 & 818.80 & 856.36 & 881.22 & 916.57 & 959.14 & 1004.50 \\
\hline May & 771.60 & 689.40 & 806.30 & 750.08 & 866.41 & 933.86 & 992.57 & 1043.11 \\
\hline June & 685.50 & 780.00 & 775.00 & 773.00 & 803.80 & 830.48 & 871.54 & 911.36 \\
\hline August & 958.40 & 809.40 & 790.60 & 902.35 & 929.90 & 983.13 & 1026.28 & 1078.17 \\
\hline September & 866.25 & 837.50 & 818.80 & 831.68 & 871.55 & 899.54 & 945.42 & 988.21 \\
\hline October & 774.10 & 762.50 & 741.94 & 746.31 & 786.62 & 809.95 & 852.47 & 890.51 \\
\hline November & 792.50 & 775.00 & 762.21 & 761.71 & 797.09 & 820.87 & 862.86 & 901.58 \\
\hline December & 890.30 & 865.60 & 858.67 & 853.68 & 892.29 & 918.40 & 965.28 & 1008.52 \\
\hline MAX (MW) & 958.40 & 865.60 & 858.67 & 902.35 & 929.90 & 983.13 & 1026.28 & 1078.17 \\
\hline
\end{tabular}

Forecasting the load and the use of transformer 3 capacity in Nusa Dua substation 
Table 7. Forecasting transformer 3 until 2020.

\begin{tabular}{|c|c|c|c|c|c|c|c|c|}
\hline Transformator 3 & 2015 (MW) & 2016 (MW) & 2017 (MW) & 2018 (MW) & 2019 (MW) & 2020 (MW) & 2021 (MW) & 2022 (MW) \\
\hline January & 625.00 & 725.90 & 712.50 & 774.27 & 826.61 & 905.32 & 984.41 & 1076.14 \\
\hline February & 522.00 & 709.70 & 812.50 & 879.51 & 962.86 & 1049.36 & 1146.63 & 1251.42 \\
\hline March & 750.00 & 800.30 & 750.00 & 845.33 & 949.59 & 1037.71 & 1138.47 & 1242.25 \\
\hline April & 718.80 & 830.00 & 781.30 & 889.50 & 939.25 & 1039.38 & 1126.44 & 1234.28 \\
\hline May & 718.80 & 771.30 & 775.00 & 806.11 & 865.38 & 940.41 & 1024.77 & 1118.40 \\
\hline June & 625.00 & 752.50 & 690.60 & 816.98 & 927.13 & 1020.79 & 1120.56 & 1224.13 \\
\hline July & 656.30 & 738.40 & 756.30 & 795.33 & 858.54 & 933.63 & 1018.17 & 1111.19 \\
\hline August & 843.80 & 771.90 & 712.50 & 872.71 & 980.99 & 1089.60 & 1192.31 & 1305.17 \\
\hline September & 791.90 & 809.40 & 771.90 & 846.04 & 940.74 & 1024.78 & 1122.85 & 1224.82 \\
\hline October & 740.00 & 825.00 & 860.46 & 900.19 & 975.30 & 1059.14 & 1156.00 & 1261.15 \\
\hline November & 783.40 & 778.10 & 774.67 & 808.57 & 874.25 & 949.40 & 1035.89 & 1130.17 \\
\hline December & 854.70 & 778.10 & 883.20 & 965.77 & 1053.71 & 1150.93 & 1256.43 & 1371.98 \\
\hline MAX (MW) & 854.70 & 830.00 & 883.20 & 965.77 & 1053.71 & 1150.93 & 1256.43 & 1371.98 \\
\hline Used Capacity (\%) & 49.35 & 47.92 & 50.99 & 55.76 & 60.84 & 66.45 & 72.54 & 79.21 \\
\hline
\end{tabular}

Forecasting results using ANFIS found that the condition of the transformer for the next 5 years is estimated to have reached more than $60 \%$, where the condition is not optimal for the parallel load maneuver need transformer. for that step necessary steps by the government and PLN anticipating the capacity of the transformer is nearing the maximum.

\section{Conclusion}

Accuracy of electric load forecasting using Adaptive Neuro-Fuzzy Inference System (ANFIS) method is better than Artificial Neural Network (ANN) method, this is indicated by MAPE resulting from weekly electrical load forecasting using ANFIS method is $0.028 \%$ while MAPE forecasting using method ANN is $51.57 \%$. ANFIS method accuracy better than ANN method is caused by membership function which is part of fuzzy inference system that can assist in the best decision making, by mapping the existing data input so that the result obtained by ANFIS method becomes more accurate than the use ANN method itself without any combination with other optimization methods.

Further researchers are expected to continue the study by involving other parameters such as weather, electrical load consumption level, and environmental temperature.

\section{References}

[1] Guilin Zheng, Li Zhang. "The Electrical Load Forecasting Base on an Optimal Selection Method of Multiple Models in DSM".2015. International Journal of Online Engineering, Vol 11 pages 8 .

[2] Donate J P, Cortez P, Sánchez G G, et al., "Time series forecast- ing using a weighted cross-validation evolutionary artificial neural network ensemble".2007. Neurocomputing, Vol. 109, No. 3, pp. 27-32.

[3] R. Palivonaite, M. Ragulskis, "Short-term time series algebraic forecasting with internal smoothing".2014. Neurocomputing, Vol. 127, No. 15, pp. 161-171.

[4] J. Shao, "Application of an artificial neural network to improve short-term road ice forecasts".1998. Expert Syst.
Appl., Vol. 14, Issue 4, pp. 471-482.

[5] Gan-qiong Li, Shi-wei Xu, Zhe-min Li. 2010. "Short-Term Price Forecasting For Agro-product Using Artificial Neural Network". Agriculture and Agricultural Science Procedia 1 (2010) 278-287.

[6] S. Kuusisto, M. Lehtokangas, J. Saarinen and K. Kashi. "Short Term Electric Load Forecasting Using a Neural Network with Fuzzy Hidden Neurons". Neural Comput \& Applic, 6: 42-56, 1997.

[7] Shiliang Sun. "Traffic Flow Forecasting Based on Multitask Ensemble Learning”. GEC'09, June 12-14, 2009, Shanghai, China.

[8] Ivan Simeonov, Hristo Kilifarev and Rajcho llarionov. "Algorithmic Realization of System for Short-term weather forecasting”. CompSysTech'07. June 14-15, 2007. University of Rousse, Bulgaria.

[9] Chiristopher Kiekintveld, Jason Miller, Patrick R. Jordan and Michael P. Wellman. "Forecasting Market Price in a Supply Chain Game". AAMAS'07 May 14-18 2007, Honolulu, Hawai'i, U.S.A.

[10] Hamidie, Kafahri Arya. 2009. "Metode Koefisien Energi Untuk Peramalan Beban Jangka Pendek Pada Jaringan Jawa Madura Bali”. Jurnal Electrical Engineering of Universitas Indonesia.

[11] Hesham K. Alfares, Mohammad Nazeeruddin. 2002. "Electric load Forecasting: literature survey and classification of methods". International Journal of System Science, Volume 33 pages 23-34.

[12] Minaye, Emiyamrew dan Matewose, Melaku. 2013. "Long Term Load Forecasting of Jimma Town for Sustainable Energy Supply". International Journal of Science and Research (IJSR), pp. 2319- 2324.

[13] Karthika. B. S, Paresh Chandra Deka. 2015. "Prediction of Air Temperature by Hybridized Model (Wavelet-ANFIS) Using Wavelet Decomposed Data". International Conference on Water Resources, Coastal and Ocean Engineering. Aquatic Procedia 4, pp. 1155-1161.

[14] Youssef Kassem, Huseyin Camur, Engin Esenel. 2017. "Adaptive neuro-fuzzy inference system (ANFIS) and response surface methodology (RSM) prediction of biodiesel dynamic viscosity at $313 \mathrm{~K}$. Procedia Computer Science 120 (2017) 521-528. 
[15] Hsin-hung Lee, Iosif I. Shinder, John D. Wright, Michael R. Moldover. 2014. "Application of ANFIS Method to the Nonnulling Calibration of Multi-Hole Pitot Tube". $37^{\text {th }}$ National Conference on Theoretical and Applied Mechanics (37th NCTAM 2013) \& the $1^{\text {st }}$ International Conference on Mechanics ( $1^{\text {st }}$ ICM). Procedia Engineering 79, pp. 125-132.

[16] Yan-liang Zhang, Jun-Hui Lei. 2017. "Prediction of Laser Cutting Roughness in Intelligent Manufacturing Mode Based on ANFIS”. Procedia Engineering 174 (2017) 82-89.
[17] Liu Junli. "Research on the Coal-rock Interface Recognition Based on the Fusion of Multi-information with ANFIS". China Coal, 2014, 12: 56-59.

[18] Log sheet by 2015, PT PLN (Persero) Area Pengatur Beban Bali.

[19] Log sheet by 2016, PT PLN (Persero) Area Pengatur Beban Bali.

[20] Log sheet by 2017, PT PLN (Persero) Area Pengatur Beban Bali. 